\title{
A internet como coadjuvante no empoderamento dos pacientes que vivem com o HIV/Aids
}

\author{
| ${ }^{1}$ Luciene Dutra Falcão, ${ }^{2}$ Helena Beatriz da Rocha Garbin, ${ }^{3}$ Lilian Koifman |
}

Resumo: Este trabalho discute o uso da internet como instrumento de pesquisa em saúde num grupo de pacientes que vivem e convivem com o HIV/Aids. A literatura sobre o tema em questão mostra a internet como um dos meios de comunicação mais acessados para busca de informaçôes sobre saúde nos dias atuais, inclusive para o grupo entrevistado. É um estudo qualitativo que envolve entrevistas semiestruturadas. Os pacientes entrevistados pela pesquisa estão em tratamento ambulatorial para HIV/Aids e participam de um grupo de apoio no mesmo hospital onde realizam seu tratamento. Em contraposição com os dados teóricos levantados, no grupo pesquisado muitos preferem o uso de outras mídias e alguns não fazem uso da internet para pesquisas sobre saúde. A análise das entrevistas revelou que o conhecimento adquirido pela internet ou por outras mídias náo afeta o respeito do profissional médico. Pelo contrário, parece valorizar a relação médico-paciente e a confiança no conhecimento médico. Apesar de utilizarem vários meios de comunicação, consideram que a principal fonte de informação ainda é aquela oferecida pelo profissional médico ou outro profissional de saúde qualificado. Além disso, o empoderamento, obtido por meio dos conhecimentos adquiridos na internet, contribuiu para o diálogo com o médico durante a consulta. Pelo contrário, fortalecido pela confiança que o profissional médico transmite ao conduzir o encontro clínico.

> Palavras-chave: HIVIAids; internet; empoderamento; relação médico-paciente.

\author{
' Enfermagem, Instituto Nacional \\ de Câncer. Rio de Janeiro-RJ, Brasil \\ (lucienefalcaoenfa@gmail.com). \\ ORCID: 0000-0001-9812-0577 \\ ${ }^{2}$ Perícia Médica, Fundação \\ Oswaldo Cruz. Rio de Janeiro-RJ, \\ Brasil (hgarbin75@gmail.com). \\ ORCID: 0000-0002-9606-9349 \\ ${ }^{3}$ Instituto de Saúde Coletiva, \\ Universidade Federal Fluminense. \\ Niterói-RJ, Brasil (liliankoifman@ \\ hotmail.com). \\ ORCID: 0000-0003-1038-3490
}

Recebido em: 27/06/2019 Aprovado em: 30/06/2019 Revisado em: 30/06/2020 


\section{Introdução}

Nos últimos 30 anos, o mundo vem sofrendo mudanças em todas as esferas, em especial a tecnológica, com grandes investimentos nesta área. Destaca-se o grande avanço das tecnologias da informação e comunicação (TICs), ampliando o acesso a todo tipo de informaçáo e mediando processos informacionais e comunicativos dos indivíduos, pois desconsidera espaços geográficos e possibilita a comunicação numa escala global e em rede. Castells (2003) aponta que no final do século XX, a internet passou a enfatizar alterações nas organizaçóes sociais e nas estruturas de base da sociedade contemporânea. Atualmente, através dos meios de comunicação de massa como o rádio, a televisão, os jornais, revistas, a internet, entre outros, é oferecida a possibilidade de se obter grandes quantidades de informaçóes. Apesar de ser relevante o papel de todas essas mídias, a internet vem assumindo destaque em todo o mundo com suas incontáveis fontes de informação.

A internet possibilita cada vez mais que os indivíduos busquem e selecionem conteúdos de seu interesse, para as mais variadas finalidades. Segundo Giddens, os indivíduos vêm assumindo uma postura cada vez mais reflexiva numa sociedade moderna de riscos:

[...] vivemos em um contexto instável e complexo de argumentos e contra-argumentos, que possibilita o reforço do pensamento de que com a ausência de um padrão definido de conceitos, ao indivíduo cabe a escolha e decisão no que ele próprio quer acreditar[...]" (GIDDENS, 2002, p. 75).

Nesse contexto, a internet deixa de ser um simples meio eletrônico de comunicação e passa a fazer parte do hábito cotidiano dos indivíduos na busca de informaçóes, fundamentada em múltiplos interesses pessoais ou coletivos. A saúde é um dos temas de ampla exposição na rede mundial de computadores e essa mídia vem sendo apontada como grande fonte de informação para leigos, com buscas facilitada pela imensa quantidade de sites sobre temas relacionados à saúde-doença (KIVITS, 2009). Tal fato tem concordância com as observaçōes de Sarah Nettleton (2004), de que o conhecimento médico se torna cada dia mais informatizado, "escapando" para fora das instituiçôes médicas tradicionais e tornando-se mais facilmente acessível. Isso vem ao encontro da ideia de que a saúde se tornou, nos últimos anos, uma das principais preocupaçôes dos seres humanos (LUPTON, 1997).

A grande rede mundial de computadores possui cada vez mais usos no campo da saúde como ferramenta facilitadora nas intervençôes terapêuticas, na promoção 
de treinamentos e educação, também define e gerencia grupos de apoio e facilita pesquisas em saúde. Possui, ainda, a capacidade de alcançar grupos tradicionalmente de difícil acesso que são representados pelos pacientes com doenças estigmatizantes, como por exemplo: HIV/Aids, depressão, ansiedade, deficientes, entre outros (WHITEHEAD, 2007).

Desde o surgimento do HIV, vários estigmas e preconceitos passaram a existir e se perpetuam até os dias atuais (PERUCCHI et al., 2014). Para o paciente, a notícia do HIV é uma experiência de grande impacto, tristeza e trauma, que muda o eixo de seu universo particular, estabelecendo uma ruptura, uma quebra e, frequentemente, um recomeço (BURY, 1982; WILLIAMS, 2000). Compreende-se que o lugar do impacto operacionaliza mudanças estruturais de grande porte na vida (como um todo e, especialmente, em sua perspectiva social) e no aspecto emocional do paciente HIV positivo (VILLELA, 2013).

As dimensôes de contaminação pandêmicas do HIV/Aids provocaram alteraçôes profundas nas relaçóes estabelecidas entre os soropositivos e suas famílias, grupo social e profissional. A Aids, por vezes, foi comparada à peste negra. Em decorrência os pacientes passaram a carregar um recorrente estigma que, mesmo sem possuir coerência técnico científica para tal comparação, pode ser reconhecido constantemente nos discursos correntes e acepções empíricas infundadas (SOUZA, 2007). O preconceito aparece associado ao diagnóstico de HIV/Aids, seja em função das experiências que são relatadas pelos próprios pacientes, ou pelo conhecimento do preconceito diretamente vinculado a doença (SILVA et al., 2015).

Em grupo, o conhecimento adquirido pela experiência da vivência e da convivência com a AIDS transforma-se em compartilhamento e força para o enfrentamento da doença. Essa forma de compartilhar o conhecimento tem obtido reconhecimento não só por cientistas sociais, mas também por autoridades públicas e demais profissionais de saúde, especialmente em função de sua importância para a diminuição dos impactos sociais e psicológicos aos pacientes que vivem com HIV/ Aids (RABEHARISOA, 2008). Portanto, as comunicaçóes desenvolvidas através da rede mundial de computadores têm se mostrado extremamente úteis e importantes para a existência dos mais variados grupos de pacientes, familiares e ativistas que se unem para debater e compartilhar temas de interesse relacionados à vivência e convivência com o HIV/Aids. Como também as associaçóes grupais constituídas em hospitais ou virtualmente, que buscam discutir e compartilhar experiências pessoais 
a respeito da doença e se colocam como um importante elemento fortalecedor para o auxílio ao enfrentamento do HIV/Aids e do empoderamento dos pacientes que vivem com a patologia em questão (COSTA; SILVA, 2013).

As associaçôes grupais que discutem e compartilham experiências pessoais (on-line ou não), além de ampliarem o conhecimento a respeito da doença, são importantes atores para o enfrentamento da doença. Nesse sentido o ciberespaço se configura como um lugar em que pessoas de todos os perfis (sociais, culturais, econômicos, religiosos) se conectam e interagem de forma rápida e fácil (FREIRE et al., 2010). O ambiente virtual tem grande capacidade de revitalização das lutas e movimentos civis onde, de forma constante, há o aumento no número de indivíduos que procuram os espaços em rede, querendo se expressar, buscar informaçóes e compartilhá-las (MORAES, 2000). Por outro lado, a internet serve como um importante complemento para a condução das açóes políticas, voltadas para o engajamento cívico, e também para a promoção de uma participação democrática de todas as partes interessadas no ativismo desenvolvido em rede. Mas isso não significa que os processos tradicionais se encontrem encerrados em consequência dessa nova dinâmica de participação (FREY, 2003).

Essa nova forma de conexão virtual mediada pelos computadores, celulares e suas ferramentas possibilita que indivíduos em comunidades virtuais compartilhem suas experiências com o adoecimento e reforça um novo perfil de paciente: o paciente expert, como são chamados em alguns estudos. Eles são indivíduos que buscam informações sobre sua saúde, ou de familiares, na internet, não só em comunidades virtuais, mas também nos incontáveis sites relacionados ao binômio saúde-doença. Freidson (1988) considera a relação médico-paciente como uma relação assimétrica, em que médicos e pacientes têm objetivos e prioridades diferentes que envolvem questôes técnicas e financeiras - enfim, uma interação que envolve conflito e luta de poder. A informação/conhecimento está na base dessa assimetria e a internet possui potencial para alterá-la (SANTANA, 2009; LEFÈVRE, 2007). Powell (2003) aponta que a internet está mudando o equilíbrio do conhecimento entre profissionais de saúde e pacientes, capacitando estes últimos a se envolverem ainda mais na tomada de decisões em saúde.

Estudos realizados recentemente pelo National Health Service (NHS), na GrãBretanha, em 2016, apontam que a internet foi usada diariamente por $82 \%$ dos adultos (41,8 milhóes), em comparação com 35\% (16,2 milhôes) em 2006. Em 2016, 
$70 \%$ dos adultos acessaram a internet, utilizando um telefone celular ou smartphone, quase o dobro de 2011 (36\%) (NHS, 2016). No Brasil, os internautas chegaram a $54,4 \%$ das pessoas com mais de 10 anos em 2014, o que corresponde a 95,4 milhóes de brasileiros com acesso à internet (IBGE, 2016). Pesquisa realizada em 2015, pelo Centro Regional de Estudos para o Desenvolvimento da Sociedade da Informação (CETIC), apurou o total de usuários da internet para 2016 em 68\%. Do total de usuários, $42 \%$ procuraram informaçôes relacionadas à saúde ou aos serviços de saúde.

O manejo com a internet viabiliza melhorias na qualidade de vida dos usuários por via do aumento da autonomia, proatividade e autoconfiança, permitindo ao usuário a criação de estratégias para enfrentamento das situações adversas em relação à saúde (LIMA et al., 2015). E esse empoderamento que pode advir do uso da internet, pode ser observado no indivíduo ou em grupos de indivíduos (GARBIN, 2012).

O empoderamento, mediante aspectos de promoção da saúde, visa possibilitar aos indivíduos e coletivos o alcance de um aprendizado que os torne efetivamente capazes de viver a vida em suas mais distintas etapas e lidar com limitaçôes impostas por eventuais enfermidades, e com a realização de açôes em ambientes tais como: na escola, no domicílio, no trabalho e nos demais coletivos comunitários (como é o caso de grupos de apoio, associaçóes de pacientes e movimentos ativistas, desenvolvidos fisicamente ou na rede), contribuem para esse empoderamento (POLAND; GREEN; ROOTMAN, 2000).

O ambiente da internet funciona como um complemento relevante e potencial para gerar autonomia e possível empoderamento. Pode auxiliar os pacientes que queiram desenvolver conhecimentos, habilidades, atitudes e autoconhecimento que se aportam como fatores necessários para que o indivíduo possa assumir efetivamente a responsabilidade de suas decisóes a respeito de sua saúde (FESTE; ANDERSON, 1995).

\section{Caminho metodológico}

Este trabalho apresenta um estudo qualitativo que envolve 11 entrevistas semiestruturadas, com indivíduos entre 18 a 85 anos, que possuem acesso à internet e às redes sociais ou não. As entrevistas foram realizadas em um hospital universitário no estado do Rio de Janeiro. Os pacientes entrevistados pela pesquisa estão em tratamento ambulatorial para HIV/Aids e participam de um grupo de apoio no 
mesmo hospital. A pesquisa se propóe a analisar a contribuição da comunicação na vivência do adoecimento entre indivíduos usuários de internet e redes sociais digitais, utilizando o exemplo do HIV/Aids.

Foi elaborado um roteiro abordando as seguintes questôes: a utilização da internet para busca de informaçôes sobre saúde em geral e sobre sua própria saúde, participação em comunidade virtual e em um grupo de apoio presencial e relação médicopaciente. A pesquisa foi elaborada em conformidade com a Resoluçáo $n^{\circ}$ 466/2012, que aprovou as diretrizes e normas que regulamentam a ética da pesquisa envolvendo seres humanos no Brasil. O Comitê de Ética e Pesquisa da Faculdade de Medicina da Universidade Federal Fluminense, foi responsável pela aprovação da pesquisa, CAAE: 79098617.0.0000.5243, submetido em 15/07/2018. Todos os participantes voluntários da pesquisa assinaram devidamente o Termo Consentimento Livre e Esclarecido (TCLE) e foi mantido o anonimato dos entrevistados.

\section{Discussão}

\section{Fontes de informaçáo e confiabilidade}

No que tange aos fatores específicos desta pesquisa, cabe dizer que oito dos entrevistados são usuários da internet para diversas finalidades e possibilidades (redes sociais diversas, acesso à notícia, pesquisas acadêmicas, pesquisas de cunho pessoal, entre outros). Somente três alegam não acessar costumeiramente e não possuem interesse. Nenhum, dentre os 11 entrevistados, relata participar de grupos on-line. Muitos rejeitam a presença em comunidades virtuais de grupos apenas constituídos por soropositivos, sob a justificativa de que as informaçóes veiculadas nesse espaço podem não ser exatas pelas diferenças existentes entre as pessoas e as possíveis reaçôes dos organismos. Alguns, entretanto, destacam que pode ser uma ideia interessante, mas defendem que os grupos com encontros físicos são mais importantes. Outros ainda pontuam que uma alternativa interessante seria a existência de comunidades nas quais participassem também profissionais da saúde.

Muitas informaçóes veiculadas na internet não possuem confiabilidade no que se refere ao seu conteúdo informativo sobre saúde, porque qualquer pessoa pode produzir conteúdo informacional e disponibilizá-lo na internet, sem que os mesmos tenham uma qualidade ou natureza comprovada cientificamente. Em estudos realizados no Brasil pela Fiocruz no laboratório LaiSS (Laboratório, Internet, Saúde e Sociedade), 
foi apurado que $75 \%$ dos sites analisados não possuem confiabilidade em seus conteúdos e somente $20 \%$ dos indicados estáo em conformidade (NETO, 2016). Fica claro nas entrevistas que os indivíduos não utilizaram critérios ou preferências de sites para a pesquisa e que realizaram busca aleatória no Google, digitando simplesmente a frase do tema de desejo para a busca. Pesquisa realizada na Alemanha em 2002 (EYSENBACH, 2001) aponta que, além de não estabelecerem critérios para sua pesquisa, os participantes utilizavam somente os primeiros links, na primeira página e raramente pesquisavam o "Quem Somos" (About Us) dos sites, isto é, o local onde podem ser encontrados os responsáveis pelo site e pelas informaçóes nele contidas.

[...] esse Correio Braziliense eu descobri sozinha, [...] porque eu 'tava' com muita dor, aí eu botei assim, título, [...] coloco título enorme: "o uso contínuo dos retrovirais causa problema "ósseo", aí caiu aqui nesse Correio Brasiliense, não foi nem "tão" difícil de achar (Entrevistado 9).

[...] aí eu vou lá e busco, só no Google mesmo, nada além disso (Entrevistado 2).

É frequente no grupo de entrevistados a utilização de outras mídias como fonte de pesquisa e informação sobre a saúde individual e coletiva. Segundo os relatos, esse tipo de busca é costumeiro, além de utilizarem a internet, utilizam jornais e televisão para se manterem informados e preferem se servir dessa informação. Sentem-se mais confortáveis e acreditam nela quando a informação é transmitida em um canal de televisão em rede nacional. Contudo, apesar dos meios de comunicação de massa como o rádio, a televisão, os jornais e revistas, oferecem a possibilidade de se obter grandes quantidades de informaçóes, a internet vem assumindo destaque em todo o mundo com suas incontáveis fontes de informação, proporcionando modificaçóes tecnológicas nas estruturas de base da sociedade (CASTELLS, 2003).

Eu assisto o Fantástico quando fala de uma medicação nova, quando tem experiências com medicação e remédios novos, como a vacina que estão dando agora, né? (Entrevistado 1).

Eu acho que a internet ajuda muito, mas eu leio jornal, eu sei tudo, eu acompanho porque eu leio jornal todo dia. [...] e assisto noticiário de televisão, estou sempre antenado, mas pela internet não (Entrevistado 3).

\section{Relação médico-paciente}

As informaçóes obtidas na internet são tanto para o paciente se manter informado, quanto para levantar informaçôes para discutir na consulta com seu médico ou outro profissional de saúde, em uma terapia ou cuidado. Muitos pacientes agora 
trazem material da Internet impresso para a consulta médica, e estão sendo relatados e percebidos benefícios aos pacientes.

[...] eu vou comentar hoje com a médica [...]. E foi o que a gente sabe mesmo, o problema é ósseo, é da medicação, não tem jeito não, entendeu? Ela mudou minha medicação, a gente vai fazer novos testes de medicação e não tem muito mistério entendeu? Ela é sempre muito atenciosa com o que falo com ela, mas é assim mesmo [...], é bom, porque quanto mais liberdade você tem com seu médico, você fica à vontade, [...], por isso que é bom ler, estudar, você pode conversar [...] você conversa, você questiona, ela (médica) te explica melhor com facilidade [...] (Entrevistado 9).

Apesar do uso da internet pelo paciente portador do HIV/Aids para obter informações sobre saúde ser cada vez mais habitual, nos relatos percebe-se a valorização e a importância de se manter a credibilidade e a confiança no profissional médico:

[...] Pra mim, muita coisa, assim, me ajuda porque eu vou ficar mais na dúvida naquilo e vou procurar meu médico, não vou assim acreditar em tudo o que eu vejo na internet, eu vou pegar aquilo e vou perguntar e eu vou procurar saber com ele, se realmente é verdade ou náo [...].

Os entrevistados demonstram valorizar o encontro médico presencialmente, prezando uma boa relação, com reflexo positivo e potencial na evolução no tratamento e na convivência com o HIV/Aids, como no relato:

Mais conhecimento me deixa mais apta a compreender o processo e eu não tenho conhecimento, ela (a médica) me explica que determinados... a reação da composição dos remédios com a outra, por isso tem que ter muito, a gente náo pode sair tomando [...]. (Entrevistado 8).

Desta feita, o encontro clínico entre médico e paciente constitui, para esses indivíduos, a oportunidade e o local considerados como ideais para que o doente consiga adquirir informaçóes sobre a sua condição. $\mathrm{O}$ médico ainda é considerado por vários entrevistados como a mais importante fonte de informaçáo de saúde, ainda assim, é relevante e crescente a importância da internet em meio ao domínio da saúde (SANTANA, 2009).

[...] eu sou paciente mas eu sou leigo, eu "tô" aqui "pra" cumprir ordem do médico, eu não entendendo nada, eu não sei de nada, se ele falar assim: "Toma veneno que você vai melhorar", eu vou tomar, ele é o médico, ele estudou pra isso, ele tem a capacidade e nós não temos. "Ah, hoje eu não vou tomar remédio, não 'tô' me sentindo bem”, eu não posso, ele mandou eu tomar (Entrevistado 2).

Embora seja notável a não oposição em relação ao hábito dos pacientes pesquisarem conteúdos de saúde ou sobre sua saúde na internet e levarem para a consulta médica 
com a intenção do esclarecimento de dúvidas, na visão deste entrevistado, seus médicos dão preferência a que os pacientes esclareçam primeiramente suas dúvidas com o profissional médico, veja:

[...] Ele não é muito radical não, ele diz: "a senhora experimenta, aí procura direitinho se a senhora tem alguma alteração ou não, porque aí eu vou conversar com você" e ele geralmente toma nota do que eu 'tô' falando e diz assim: "eu mesmo vou pesquisar pra você. (Entrevistado 5).

Há uma crescente discussão a respeito do fato de que assuntos pesquisados na internet podem atrapalhar mais do que empoderar o paciente com HIV/Aids. Em estudo de cunho semelhante, realizada no Rio de Janeiro em 2011 (GARBIN, 2012), há relatos de impactos negativos. Tal pode ocorrer em função da descoberta de possíveis quadros evolutivos, da leitura de efeitos colaterais de medicamentos, da confirmação da não existência de cura, enfim, da revelaçáo das falhas do conhecimento científico, ampliando os níveis de incerteza da vida na modernidade. Em especial em um grupo que viveu o desconhecimento completo sobre sua patologia e vive as mudanças constantes das certezas médicas. E esse impacto pode ser visto aqui, na fala de um entrevistado:

[...] Eu, na minha opinião, eu acho que atrapalha, porque é um assunto muito delicado

[...]. Olha, influencia absurdamente, por exemplo, eu, abalou bastante a minha mente, psicologicamente [...], assuntos de que, não tem cura, da doença, né, fica só, você fazendo o tratamento direitinho, fica indetectável só, mas não tem cura (Entrevistado 11).

\section{Estigma e anonimato}

Os relatos revelam um grande receio dos pacientes. Demonstram medo com a exposição pública, preocupação com possíveis consequências negativas dessa revelação em sua vida pessoal e profissional. E, partindo desses receios, muitas pessoas que vivem com HIV/Aids optam por viver sobre total anonimato. A percepção desse estigma com a soropositividade/Aids faz com que alguns entrevistados busquem não revelar suas experiências para outros com medo do preconceito das pessoas e, também, do preconceito interiorizado com relação a sua condição clínica, como mostram alguns trechos, por exemplo:

[...] eu tenho muito medo da empresa, porque é muita gente e de repente eu ficaria.... não sei se seria bom ou se seria ruim, entendeu? [...] Não me exponho, tenho medo [...]. Eu posso até, 'de repentemente', trocar conversas, mas nunca dizer, não gostaria que [...]. 
Percebemos, através das entrevistas, que a internet emerge e se estrutura como um espaço no qual as pessoas podem permanecer sob anonimato se assim desejarem. E podem se expor, até como ativistas nas causas que sejam de seu interesse em qualquer que seja a forma.

\section{Considerações finais}

A utilização da internet para pesquisas em saúde ou sobre a saúde dos pacientes, em especial os soropositivos, continua aumentando conforme expressam os artigos estudados. E, ao mesmo tempo, para alguns pacientes que se voluntariaram para a pesquisa, a informação fornecida no encontro clínico ainda é tida como a principal fonte de informação em saúde ou sobre sua saúde. Na fala de alguns, "mais vale à pena ouvir o saber médico do que os comentários na internet sobre determinados assuntos relacionados à saúde ou doença”. E revelam que a busca em rede é necessária para manterem-se atualizados com o que a biomedicina tem a oferecer em relação às novas tecnologias médicas.

Náo podemos desconsiderar que a pesquisa sobre saúde ou doença enquanto informação de saúde sempre existiu, sendo ela desenhada e realizada de forma intrinsecamente particular para cada indivíduo portador de uma doença. Seja pela internet ou por outros meios de comunicação em massa, ela se dá de acordo com a preferência de cada um. Mas a internet possibilitou o acesso de maneira considerável a conteúdos médicos, facilitando ao paciente buscar informaçóes, questionar com o seu médico ou mesmo procurar um melhor caminho para o seu tratamento, promoção de saúde e qualidade de vida.

Neste estudo, o que se pode constatar é que a relação médico-paciente ainda é baseada na confiança e no entendimento em comum das partes. E que o empoderamento do paciente foi percebido pelo acesso às informaçôes obtidas na internet, mas não significa que abale ou interfira negativamente no relacionamento médico-paciente ou na confiança entre ambos. Foi possível apreender das entrevistas que o amplo acesso a informaçóes médico-científicas não abalou a confiança no profissional médico; que o poder médico se faz presente e atuante nas condutas médicas, mesmo quando com pacientes empoderados e autônomos. Mantêmse, portanto, a submissão e a aceitação das condutas estabelecidas pela medicina científica, através de seus médicos. 
Como resultados do desenvolvimento da pesquisa, encontramos que as representaçóes sociais existentes nos grupos de discussão e de disseminação de informaçôes a respeito do vírus HIV na internet, possibilitaram em diferentes graus e perspectivas o alcance de uma melhor vivência e convivência de pacientes com HIV/ Aids. Contudo, ainda existe uma grande resistência dos pacientes com idade mais avançada para utilizar a internet como fonte de pesquisa em saúde ou para sua saúde.

De forma geral, percebe-se na literatura sobre o tema, que a Internet, como um todo - e as redes sociais em especial - podem ser utilizadas de modo a promover modificaçôes na realidade e nas representaçôes sociais. No caso específico dos soropositivos, é relevante para proporcionar a circulação de conhecimento para o enfrentamento da AIDS em grupos de apoio, associaçóes de pacientes e movimentos ativistas.

Tal como evidenciado e corroborado anteriormente, observa-se que a internet se constitui em elemento que abriu espaço para o alcance de uma demanda que proporcionou efetivo exercício da cidadania das mais diversas formas. Assim, em meio ao ambiente cibernético, as barreiras sociais são menos marcadas, especialmente em função da operacionalização de ferramentas digitais. E assim, mesmo que grande parcela dos pacientes soropositivos ainda não possua pleno domínio das potencialidades proporcionadas por tal tecnologia, a capacidade de empoderamento com a busca de suporte e informaçóes na internet e redes sociais tem-se mostrado efetiva, no sentido de que ela oferece possibilidades à criação de qualquer que seja a ferramenta comunicacional, seja pela internet ou náo.

Com esta pesquisa, objetivamos contribuir para a discussão sobre o entendimento acerca da eficácia e eficiência de algumas das experiências com o empoderamento de pacientes soropositivos por intermédio da aquisição de conhecimentos sobre sua saúde, com foco específico no uso da Internet e das redes sociais. Esperamos que outros trabalhos futuros colaborem para o aprofundamento da discussão, na perspectiva de aumento da autonomia dos usuários e da melhora da comunicação entre médicos e pacientes vivendo com AIDS e outras doenças crônicas. ${ }^{1}$

\section{Referências}

CASTELLS, M. A galáxia da Internet: reflexôes sobre a internet, os negócios e a sociedade. Traduçáo Maria Luiza X. de A. Borges; revisão Paulo Vaz. Rio de Janeiro: Jorge Zahar, 2003. 
COSTA, S. L. M.; SILVA, C. C.G. Usos da Internet pelo ativismo contra o HIVIAids no Brasil. In: Encontro Nacional de História da Mídia., 9. Universidade Federal de Ouro Preto. Ouro Preto: UFOP, 2013.

EYSENBACH, G.; JADAD, A. R. Evidence-based Patient Choice and Consumer Health informatics in the Internet age. J Med Internet Res., v. 3, n, 2, p. e19, 2001.

FREIRE, B. J. et a. Paixão, ciúme e traição: "liquidez" das relações humanas no ciberespaço. In: INTERCOM. Sociedade Brasileira de Estudos Interdisciplinares da Comunicação. XXXIII Congresso Brasileiro da Comunicação. Caxias do Sul: INTERCOM, 2010.

FESTE, C.; ANDERSON, E. M. Empowerment: from philosophy to practice. Patient Education Counselling, v. 26, n. 1-3, p. 139-144,1995.

FREY, K. Desenvolvimento sustentável local na sociedade em rede: o potencial das novas tecnologias de informação e comunicação. Revista de Sociologia e Política, Curitiba, n. 21, p. 165-185, nov. 2003.

GARBIN, H. B. R. Empowerment ou medicalização? Reflexôes sobre o uso da Internet para obtenção de informaçóes em saúde. Tese (Doutorado em Ciências) - Saúde Pública, ENSP, Fundação Oswaldo Cruz, Rio de Janeiro, 2012. Disponível em: http://www.periodicos.capes. gov.br>. Acesso em: 13 jul. 2017.

GIDDENS, A. A modernidade e identidade. Rio de Janeiro: Jorge Zahar, 2002. Livro digital. Disponível em: <http://www.pt.slideshare.net/adautonogueirajorge/giddens-anthonymodernidade-e-identidade> . Acesso em: 28 ago. 2017.

BURY, M. Chronic illness as biographical disruption. Sociology of Health \& Illness, v. 4, n. 2, July, 1982.

INSTITUTO BRASILEIRO DE GEOGRAFIA E ESTATÍSTICA. Pnad, 2004.Disponível em: <https: www.ibge.gov.br>. Acesso em: 19 set. 2017.

KIVITS, J. Everyday health and the internet: a mediated health perspective on health information seeking. Sociology of Health \& Illness, v. 31, n. 5, 2009.

LEFÈVRE, F. Hipertrofia das mediaçóes, Internet e empoderamento no campo da saúdedoença. Saúde e Sociedade. São Paulo, v. 16, n. 3, 2007. Disponível em: http://www.periodicos. capes.gov.br. Acesso em: 17 fev. 2017.

LUPTON, D. Doctors on the medical profession. Social Health Illness, v. 19, n, 4, p. 480-497, 1997.

MORAES, D. Comunicação virtual e cidadania: movimentos sociais e políticos na Internet. Revista Brasileira de Ciências da Comunicação, v. 23, n. 2, p. 142-155, 2000.

NETO, A. F. P. A qualidade da informaçâo em saúde na web:análise da experiência desenvolvida pelo laboratório Internet, Saúde e Sociedade. Repositório de Produção Científica. Congresso Brasileiro de Ciências Sociais e Humanas em Saúde, 7., Anais..., p. 121-122, Cuiabá-MT, 2016. 
NETTLETON, S. The emergence of E-scaped medicine? Sociology, n. 661, p. 200438, 2004. DOI: 10.1177/0038038504045857. Disponível em: <http:// www.edhare.soton.ac.UK/8811/4/ sociology-2004-Nettleton 661-79[1] pdf.>. Acesso em: 28 set. 2017.

PERUCCHI, J. et al. Psicologia e políticas públicas em HIV/Aids: algumas reflexões. Psicologia \&. Sociedade, v. 23, p. 72-80, 2011.

POLAND, B. D.; GREEN, L. W.; ROOTMAN, I. (Ed.). Settings for Health Promotion: linking theory and practice. Thousand Oaks: Sage Publications, 2000.

POWELL, J. A.; DARVELL, M. A.; JAM, G. M. A. The doctor, the patient and the worldwide web: how the internet is changing healthcare. Journal of the Royal Society of Medicine, v. 96, p. 74-75, 2003.

RABEHARISOA, V. Experience, knowledge and empowerment: the increasing role of patient organizations in staging, weighting and circulating experience and knowledge. In: AKRICH, M. et al. (Eds.). The dynamics of patient organizations in Europe. Paris, 2008. p. 13-34.

SILVA, L. C. et al. Impacto psicossocial do diagnóstico de HIV/aids em idosos atendidos em um serviço público de saúde. Revista Brasileira de Geriatria e Gerontologia, Rio de Janeiro, v. 18, n. 4, p. 841, 2015.

SANTANA, S. Tendências na utilização da Internet para questôes de saúde e doença em Portugal 2005-2007. Acta Médica Portuguesa, v. 22, n. 1, supl. 1, p. 5-14, 2009.

SOUZA, D. D. O paciente de AIDS no contexto da ajuda psicológica. 2007. Disponível em: <http://www.redepsi.com.br/2007/07/04/o-paciente-de-aids-no-contexto-da-ajuda-psicolgica/>. Acesso em: 28 set. 2017.

TIC DOMICÍLIOS. Tecnologia de informação e Comunicação em Domicílio. <http://cetic.br/ tics/usuarios/2015/total-brasil/C6/>. Acesso em: 28 set. 2017.

VILLELA, A. B. A atualidade da psicanálise: do HIV à escuta pulsional. Cadernos de Psicanálise - CPRJ. Rio de Janeiro, v. 35, n. 29, p. 77-87, 2013.

WHITEHEAD, C. L. Methodological and ethical issues in internet- intermediated research in the field of health: An integrated review of the literature. Social Science \& Medicine, v.65, issue. 4, p. 782-791, 2007.

\section{Nota}

${ }^{1}$ L. D. Falcão, H. B. R. Garbin e L. Koifman participaram da concepção, delineamento, discussão dos resultados, revisão e aprovação da versão final. 


\section{Abstract}

\section{The Internet as an adjunct to the empowerment of patients living with HIVI Aids}

This paper discusses the use of the Internet as a tool for health research in a group of patients living with HIV / Aids. The literature shows the internet as one of the most accessed media for searching for health information in the present day, including the group interviewed. We conducted a qualitative study involving 11 semi-structured interviews. All patients interviewed are HIV positives and in treatment for HIV/Aids. They are members of a support group at the same hospital they are outpatients. In opposition to theoretical data, among those interviewed, many prefer the use of other medias. Some of the interviewed in this study does not use the Internet as a mean to research health subjects. The analysis of the interviews revealed that knowledge acquired through the internet or other media, does not affect the respect of the medical professional. On the contrary, it seems to value the physician-patient relationship and the trust in medical knowledge. Despite using several means of communication, they consider that the main source of information still is the one offered by the medical professional or another qualified health professional. Moreover, that empowerment, gained through the knowledge acquired on the internet, contributed to the dialogue with the physician during the appointment. Thus, for the interviewees, the physician-patient relationship has not been compromised; on the contrary, strengthened by the trust that the medical professional shows in conducting the clinical encounter.

> Keywords: HIV /Aids; internet; empowerment; patientphysician relationship. 